\title{
PENYELESAIAN MASALAH NILAI BATAS DENGAN METODE SHOOTING LINIER
}

\author{
NIKE MULVA ENILA, SUSILA BAHRI, MONIKA RIANTI HELMI \\ Program Studi Matematika, \\ Fakultas Matematika dan Ilmu Pengetahuan Alam, Universitas Andalas, \\ Kampus UNAND Limau Manis Padang, Indonesia, \\ nikemulvaenila@gmail.com
}

\begin{abstract}
Abstrak. Berbagai masalah, baik dalam kehidupan sehari-hari maupun fenomena alam dapat diungkapkan dalam suatu model matematika yang disebut dengan masalah persamaan diferensial. Masalah persamaan diferensial terbagi dua yaitu masalah nilai awal dan masalah nilai batas. Masalah-masalah tersebut dapat diselesaikan secara numerik. Salah satu metode numerik yang dapat dugunakan adalah Metode Shooting. Dalam proses penggunaan metode tersebut, masalah nilai batas direduksi menjadi dua masalah nilai awal. Kemudian masalah nilai awal tersebut diselesaikan dengan menggunakan Metode Runge-Kutta orde empat. Untuk kemudahan dalam proses komputasi, digunakan software Microsoft Excel.
\end{abstract}

Kata Kunci: Masalah Nilai Awal, Masalah Nilai Batas, Metode Shooting, Metode RungeKutta Orde Empat

\section{Pendahuluan}

Masalah nilai awal dan masalah nilai batas dapat diselesaikan secara numerik. Salah satu cara untuk menyelesaikan masalah-masalah tersebut adalah dengan menggunakan metode shooting. Metode shooting lebih mudah digunakan dalam menyelesaikan masalah nilai batas dibandingkan metode lain seperti deret fourier. Metode shooting merupakan metode yang digunakan untuk menyelesaikan masalah nilai batas dengan cara mereduksi masalah nilai batas menjadi masalah nilai awal. Kemudian ditentukan solusi masalah nilai awal tersebut. Metode yang digunakan untuk menyelesaikan masalah nilai awal adalah metode Runge-Kutta orde empat. Metode Runge-Kutta orde empat memiliki ketelitian yang lebih akurat dibandingkan metode-metode numerik lainnya. Dalam penggunaan metode Runge-Kutta orde empat, perlu ditetapkan terlebih dahulu ukuran langkah yang disimbolkan dengan $h \cdot[2]$

\section{Persamaan Diferensial}

Persamaan diferensial adalah persamaan yang memuat turunan satu atau lebih variabel bebas. Persamaan diferensial dapat dibedakan menjadi dua yaitu:

(1) Persamaan Diferensial Biasa.

Persamaan diferensial biasa adalah persamaan yang memuat turunan satu variabel bebas. 
Definisi 2.1. [1] Suatu persamaan diferensial biasa orde $n$ adalah suatu persamaan yang dapat ditulis dalam bentuk

$$
y^{(n)}=F\left(y, y^{\prime}, \cdots, y^{(n-1)}\right)
$$

dengan $y, y^{\prime}, y^{\prime \prime}, \cdots, y^{(n-1)}$ semua nilainya ditentukan oleh $x$.

(2) Persamaan Diferensial Parsial.

Persamaan diferensial parsial adalah persamaan diferensial yang memuat turunan dua atau lebih variabel bebas. Persamaan diferensial biasa order $n$ dikatakan linier jika dapat dinyatakan dalam bentuk:

$$
a_{n}(x) y^{(n)}(x)+a_{n-1}(x) y^{(n-1)}(x)+\cdots+a_{1}(x) y^{\prime}(x)+a_{0}(x)=f(x) .
$$

\subsection{Masalah Nilai Awal}

Masalah nilai awal adalah sebuah masalah yang melibatkan satu atau lebih fungsi yang tidak diketahui beserta turunan-turunannya dalam sebuah persamaan yang memenuhi syarat awal yang diberikan.

\subsection{Masalah Nilai Batas}

Masalah nilai batas adalah persamaan diferensial biasa bersama-sama dengan kondisi yang melibatkan nilai-nilai solusi dan/atau turunannya di dua titik atau lebih. Banyak kondisi sama dengan orde persamaan diferensial.

\subsection{Metode Runge-Kutta Orde Empat}

Metode Runge-Kutta orde empat adalah metode yang sangat populer digunakan karena cukup akurat, stabil dan mudah diprogram. Bentuk metode Runge-Kutta orde empat adalah:

$$
\begin{aligned}
y_{i+1} & =y_{i}+\frac{1}{6}\left(k_{1}+2\left(k_{2}+k_{3}\right)+k_{4}\right), i=0,1,2, \cdots, n, \text { dengan } \\
k_{1} & =h f\left(x_{i}, y_{i}\right) \\
k_{2} & =h f\left(x_{i}+\frac{h}{2}, y_{i}+\frac{k_{1}}{2}\right) \\
k_{3} & =h f\left(x_{i}+\frac{h}{2}, y_{i}+\frac{k_{2}}{2}\right) \\
k_{4} & =h f\left(x_{i}+h, y_{i}+k_{3}\right)
\end{aligned}
$$

Sehingga persamaan Runge-Kutta orde empat menjadi:

$$
\begin{aligned}
y_{i+1}= & y_{i}+1 / 6\left(h f\left(x_{i}, y_{i}\right)+2\left(h f\left(x_{i}+h / 2, y_{i}+k_{1} / 2\right)\right)\right. \\
& \left.+2\left(h f\left(x_{i}+h / 2, y_{i}+k_{2} / 2\right)\right)+h f\left(x_{i}+h, y_{i}+k_{3}\right)\right) .
\end{aligned}
$$

\section{Pembahasan}

\subsection{Metode Shooting Linier}

Metode shooting linier adalah salah satu metode yang digunakan untuk menyelesaikan masalah nilai batas secara numerik. Metode ini juga menggunakan metode- 
metode yang dipakai dalam menyelesaikan masalah nilai awal. Metode ini memiliki langkah-langkah sebagai berikut: [3]

(1) Reduksi suatu masalah nilai batas menjadi dua masalah nilai awal.

Pandang masalah nilai batas linier orde dua dalam bentuk

$$
x^{\prime \prime}=p(t) x^{\prime}(t)+q(t) x(t)+r(t), a \leq t \leq b
$$

dengan $x(a)=\alpha, x(b)=\beta$.

Misalkan $u(t)$ adalah solusi tunggal untuk masalah nilai awal

$$
u^{\prime \prime}=p(t) u^{\prime}(t)+q(t) u(t)+r(t)
$$

dengan $u(a)=\alpha$ dan $u^{\prime}(a)=0$,

dan $v(t)$ adalah solusi tunggal untuk masalah nilai awal

$$
v^{\prime \prime}=p(t) v^{\prime}(t)+q(t) v(t) .
$$

dengan $v(a)=0$ dan $v^{\prime}(a)=1$.

(2) Tentukan $u(t)$ dan $v(t)$ dengan menggunakan metode Runge-Kutta orde empat.

(3) Tentukan kombinasi linier $x(t)$ dengan

$$
x(t)=u(t)+C v(t)
$$

adalah solusi untuk $x^{\prime \prime}=p(t) x^{\prime}(t)+q(t) x(t)+r(t)$ yang diperoleh dari

$$
\begin{aligned}
x^{\prime \prime} & =u^{\prime \prime}+C v^{\prime \prime}, \\
& =p(t) u^{\prime}(t)+q(t) u(t)+r(t)+p(t) C v^{\prime}(t)+q(t) C v(t), \\
& =p(t)\left(u^{\prime}(t)+C v^{\prime}(t)\right)+q(t)(u(t)+C v(t))+r(t), \\
& =p(t) x^{\prime}(t)+q(t) x(t)+r(t) .
\end{aligned}
$$

Solusi $x(t)$ pada persamaaan (3.4) mempunyai nilai batas,

$$
\begin{aligned}
& x(a)=u(a)+C v(a)=\alpha+0=\alpha \\
& x(b)=u(b)+C v(b) .
\end{aligned}
$$

Dengan substitusi kondisi batas $x(b)=\beta$ ke persamaan (3.5) diperoleh $C=(\beta-$ $u(b)) / v(b)$. Oleh karena itu, jika $v(b) \neq 0$ maka solusi khusus untuk persamaan (3.1) adalah

$$
x(t)=u(t)+\frac{\beta-u(b)}{v(b)} v(t) .
$$

\subsection{Contoh}

(1) Selesaikan masalah nilai batas

$$
x "(t)=2 t /\left(1+t^{2}\right) x^{\prime}(t)-2 /\left(1+t^{2}\right) x(t)+1 .
$$

dengan $x(0)=1,25$ dan $x(4)=-0,95$. pada interval $[0,4]$ Fungsi $p, q$, dan $r$ adalah $p(t)=2 t /\left(1+t^{2}\right), q(t)=-2 /\left(1+t^{2}\right)$, dan $r(t)=1$. Metode Runge-Kutta orde empat dengan ukuran langkah $h=0,2$ digunakan untuk mengkonstruksi solusi numerik $\left\{u_{j}\right\}$ dan $\left\{v_{j}\right\}$ ke persamaan (3.2) dan (3.3). 
Misalkan $u(t)$ adalah solusi tunggal dari masalah nilai awal

$$
u^{\prime \prime}(t)=2 t /\left(1+t^{2}\right) u^{\prime}(t)-2 /\left(1+t^{2}\right) u(t)+1,
$$

dengan $u(0)=1,25$ dan $u^{\prime}(0)=0$. Misalkan

$$
\begin{aligned}
& \frac{d u}{d t}=y=f(t, u, y), u(0)=1,25 \\
& \frac{d y}{d t}=\left(\frac{2 t}{1+t^{2}}\right) u^{\prime}(t)-\frac{2}{1+t^{2}} u(t)+1=g(t, u, y), \\
& \frac{d u}{d t}(0)=y(0)=0 .
\end{aligned}
$$

Dengan menggunakan ukuran langkah $h=0,2$ maka untuk $i=0$

$$
\begin{aligned}
k_{1} & =0 & k_{3} & =-0,030 \\
l_{1} & =-0,3 & l_{3} & =-0,295 \\
k_{2} & =-0,03 & k_{4} & =-0,059 \\
l_{2} & =-0,301 & l_{4} & =-0,292
\end{aligned}
$$

Selanjutnya diperoleh

$$
\begin{aligned}
u_{0+1} & =u_{0}+\frac{k_{1}+2\left(k_{2}+k_{3}\right)+k_{4}}{6} \\
u_{1} & =u_{0}+\frac{0+2(-0,03+(-0,030))+(-0,059)}{6} \\
& =1,25-0,1792138 \\
& =1,220 .
\end{aligned}
$$

Dari hasil penghitungan di atas dapat dilihat $u(0,2) \approx u_{1}=1,220$, dengan cara yang sama langkah di atas diulang hingga diperoleh $u(4) \approx u_{20}=-2,783$ dan

$$
\begin{aligned}
y_{0+1} & =y_{0}+\frac{l_{1}+2\left(l_{2}+l_{3}\right)+l_{4}}{6} \\
y_{1} & =y_{0}+\frac{-0,3+2(-0,301+(-0,295))+(-0,292)}{6} \\
& =0-0,297 \\
& =-0,297 .
\end{aligned}
$$

Dari hasil penghitungan di atas dapat dilihat $y(0,2) \approx y_{1}=-0,297$, dengan cara yang sama langkah di atas diulang hingga diperoleh $y(4) \approx y_{2} 0=0,021$.

Kemudian angggap $v(t)$ adalah solusi khusus masalah nilai awal

$$
v^{\prime \prime}(t)=2 t /\left(1+t^{2}\right) v^{\prime}(t)-2 /\left(1+t^{2}\right)
$$

dengan $v(0)=0$ dan $v^{\prime}(0)=1$. Misalkan

$$
\begin{array}{ll}
\frac{d v}{d t}=z=f(t, u, z), v(0)=0 & \text { dan } \\
\left.\frac{d z}{d t}=\frac{2 t}{1+t^{2}}\right) v^{\prime}(t)-\frac{2}{1+t^{2}} v(t)=g(t, u, z), & \\
\frac{d v}{d t}(0)=z(0)=0 . &
\end{array}
$$


Dengan menggunakan ukuran langkah $h=0,2$ maka untuk $i=0$ diperoleh

$$
\begin{array}{ll}
p_{1}=0,2 & p_{3}=0,2 \\
q_{1}=0 & q_{3}=0 \\
p_{2}=0,2 & p_{4}=0,2 \\
q_{2}=0 & q_{4}=0
\end{array}
$$

Selanjutnya diperoleh

$$
\begin{aligned}
v_{0+1} & =v_{0}+\frac{p_{1}+2\left(p_{2}+p_{3}\right)+p_{4}}{6} \\
v_{1} & =v_{0}+\frac{0,2+2(0,2+0,2)+0,2}{6} \\
& =0+\frac{1,2}{6} \\
& =0,2
\end{aligned}
$$

Dari hasil penghitungan di atas dapat dilihat $v(0,2) \approx v_{1}=0,2$, dengan cara yang sama langkah di atas diulang hingga diperoleh $v(4) \approx v_{20}=4$, dan

$$
\begin{aligned}
z_{0+1} & =z_{0}+\frac{q_{1}+2\left(q_{2}+q_{3}\right)+q_{4}}{6} \\
z_{1} & =z_{0}+\frac{0+2(0+0)+0}{6} \\
& =1+\frac{0}{6} \\
& =1
\end{aligned}
$$

Dari hasil penghitungan di atas dapat dilihat $z(0,2) \approx z_{1}=1$, dengan cara yang sama langkah di atas diulang hingga diperoleh $z(4) \approx z_{20}=1$.

Selanjutnya misalkan

$$
w_{i}=\frac{\beta-u(4)}{v(4)} v_{i}
$$

sehingga persamaan (6.6) dapat ditulis $x(t)=u(t)+w_{i}$ perhatikan bahwa

$$
w_{i}=\frac{\beta-u(4)}{v(4)} v_{i}
$$

selanjutnya substitusi $\beta=-0,95, u(4) \approx u_{20}=-2,782610122$ dan $v(4) \approx v_{20}=4 k e w_{i}$

$$
w_{i}=\frac{(-0,95)-(-2,782610122)}{4} v_{i}=0,45815253 v_{i} .
$$

untuk $w_{0}=0,45815253 v_{0}=0,458152530=0$

$$
\begin{aligned}
w_{1} & =0,45815253 v_{1}=0,458152530,2 \\
& =0,091630506,
\end{aligned}
$$


dengan cara yang sama hitung hingga diperoleh $w_{20}$. Selanjutnya hitung $x(t)$ dengan cara:

$$
\begin{aligned}
x(t) & =u(t)+w_{i} \\
x(0) & =u(0)+w_{0} \\
& =1,25+0 \\
& =1,25
\end{aligned}
$$

dengan cara yang sama langkah di atas diulang hingga diperoleh

\begin{tabular}{|c|c|c|c|}
\hline 2. & in. & $w$ & $x_{2}-n_{2}+w_{n}$ \\
\hline 0 & 1,250000001 & 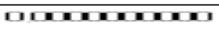 & 1,25000000 \\
\hline 0,2 & 1,220133135097 & 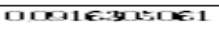 & 1,311 Te, 3658 \\
\hline 0,1 & 1,120052520171 & 01020610120 & 1,315912305023 \\
\hline 0,6 & 0,0016207131 & 0274.80151 .83 & $1,26 \cos 122314$ \\
\hline 0,3 & $0,3036-837004$ & $0 \operatorname{sect} 220244$ & 1,1 acos $\pi 248$ \\
\hline 1 & 0,57621002473 & 04581525305 & 1,0343617778 \\
\hline 1,2 & 0,3171121001 & 0541078301066 & 0, sefentabet \\
\hline 1,4 & 0,02343261404 & 06414135427 & $0,675728<2831$ \\
\hline $1, \epsilon$ & $-0,2644442500$ & 0732804404.83 & 0,1682504800 \\
\hline 1,3 & $-0,5718337258$ & 0.8246745540 & 0,2528407562 \\
\hline 2 & $-0,830$ sed 151 & $0516: 35=610$ & 0,0354390460 \\
\hline 22 & $-1,134050056$ & 10070355672 & $-0,17 \pi 02345024$ \\
\hline 2,4 & $-1,47 \pi 9121720$ & 10005661733 & $-0,378346007$ \\
\hline 2,6 & $-1,7533827 x 00$ & 1.911205794 & $-0,5626962205$ \\
\hline 2,8 & 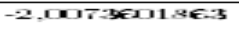 & 1282827 WSEs & $-0,724=331000$ \\
\hline 3 & $-2,23331385447$ & 13744575916 & $-0,35 \operatorname{sen} 12531$ \\
\hline 3,2 & $-2,42629133575$ & 1 hefersangt & 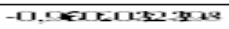 \\
\hline 3,1 & 2,2021173067 & $125 \% 7196250$ & 1,001 1 207020 \\
\hline 3,6 & $-2,6 x-26 x+102$ & 16.103451200 & $-1,04601502503$ \\
\hline 3,3 & $-2,7644325481$ & 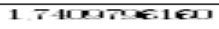 & $-1,0023520251$ \\
\hline 4 & $-2,7826101221$ & 13206101221 & $-0,25000000$ \\
\hline
\end{tabular}
$x(4) \approx x_{20}=-0,95$.

Tabel 6.2.1: Solusi Aproksimasi $\left\{x_{i}\right\}=\left\{u_{i}+w_{i}\right\}$ untuk persamaan

$$
x^{\prime \prime}(t)=\frac{2 t}{1+t^{2}} x^{\prime}(t)-\frac{2}{1+t^{2}} x(t)+1
$$

Gambar 3.1: Solusi Aproksimasi $\left\{x_{i}\right\}=\left\{u_{i}+w_{i}\right\}$ untuk persamaan

$$
x^{\prime \prime}(t)=\frac{2 t}{1+t^{2}} x^{\prime}(t)-\frac{2}{1+t^{2}} x(t)+1
$$

\section{Kesimpulan}

Berdasarkan hasil yang diperoleh pada bab pembahasan, dapat disimpulkan bahwa metode shooting dapat dijadikan sebagai salah satu alternatif dalam menyelesaikan masalah nilai batas. Metode yang merupakan langkah penyelesaian secara numerik ini diaplikasikan dengan cara mereduksi masalah nilai batas menjadi masalah nilai awal. Selanjutnya masalah nilai awal tersebut diselesaikan dengan menggunakan metode Runge-Kutta orde empat untuk mendapatkan solusi masalah nilai batas. 


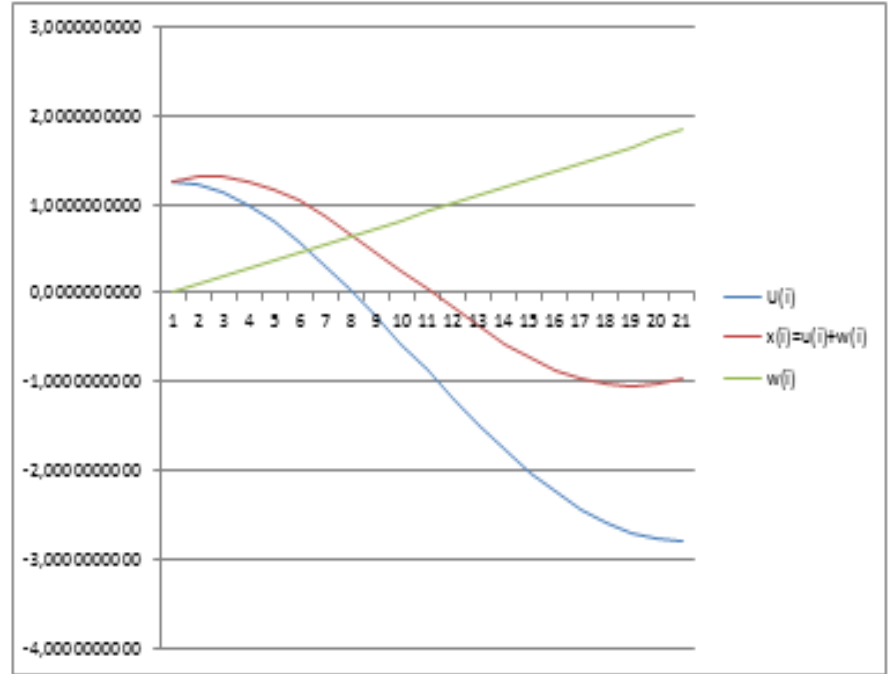

\section{Ucapan Terima kasih}

Penulis mengucapkan terima kasih kepada Bapak Dr. Ahmad Iqbal Baqi, Bapak Zulakmal, M.Si, dan Ibu Nova Noliza Bakar, M.Si sebagai tim penguji yang telah membaca dan memberi pengarahan serta saran untuk perbaikan isi dan penulisan skripsi ini.

\section{Daftar Pustaka}

[1] Chapra, Steven C. 2012. Applied Numerical Methods with MATLAB for Engineers and Scientists, Edisi Ketiga. Raghothaman Srinivasan, New York.

[2] Finizio. N dan Ladas, G, alih bahasa Santoso, Widiarti. 1998. Persamaan Diferensial Biasa Dengan Penerapan Modern, Edisi Kedua. Erlangga, Jakarta.

[3] Mathews, J.H dan Fink, K. D. 2004. Numerical Methods Using Matlab. PrenticeHall Inc, USA.

[4] Powers, D. L. 2006. Boundary Value Problems and Partial Differensial Equation. Elsevier Inc. All rights reserved, Tokyo.

[5] Ray, A.K dan Gupta, S.K. 2004. Mathematical Methods in Chemical and Environmental Engineering. Edisi Kedua. UIC Building, Singapore. 